\title{
Supporting Learners in a Time of Crisis
}

\author{
Lin Carver \\ School of Education and Social Services \\ Saint Leo University, Saint Leo, Florida, United States
}

\begin{abstract}
The COVID-19 pandemic has had significant impact on children's education. Because of school closures, instruction has moved online. This move to digital learning has brought with it significant barriers and challenges as evidenced by news articles and observations from teachers and students. Administrators, teachers, guidance counselors, lunch workers, business partners, and volunteers are banding together to meet the needs of students in this time of crisis.
\end{abstract}

Keywords: Online instruction; Coronavirus; COVID-19; K-12, Supporting learners.

\section{INTRODUCTION}

In this unprecedented time of global crisis with more than 1,700,000 cases of the Coronavirus worldwide, the social, economic, and educational consequences are staggering. Higher education and PK-12 institutions are being closed in extraordinary numbers. On March $6^{\text {th }}, \mathrm{ABC}$ News reported that COVID-19 was responsible for the disruption of 290 million students' educations worldwide [1]. Just about a week later, on March $13^{\text {th }}$, the World Economic Forum reported that over 421 million children in 39 countries had been affected by school closures. This number did not include those students who were impacted by the more localized school closures happening in another 22 countries [2]. As of April 11 $1^{\text {th }}$, that number grew to encompass about $91 \%$ of the learners enrolled in PK through high school settings, or about 1,500,000 learners worldwide [3].

Previously health issues or natural emergencies have caused temporary localized school closures for short periods of time; however, "the global scale and speed of the current educational disruption is unparalleled and, if prolonged, could threaten the right to education" [1]. The COVID-19 pandemic has had significant educational, social, and economic impacts on children and families, creating stress and challenges for children who are caught in the middle.

Schools have not wasted any time responding to this crisis, they have quickly maneuvered themselves to be able to provide instruction through every possible medium in an attempt to support children. Communities, businesses, and educators have banned together. Educators are doing what good teachers have always done, going above and beyond to meet the needs of their students. Even though schools have closed, learning has not ended. 


\section{Impact on Instruction}

\section{CHALLENGES}

With school closures, instruction has shifted from a face to face venue to other means. It is being provided through teacher-created online content, digital content available from providers, paper packets, one to one instruction at safe social distances, and in a combination of whatever ways available. The ingenuity of educators is evidenced through a picture of a teacher with his whiteboard demonstrating to a student through her closed glass storm door how to do her math work. Educators are doing whatever they can to reach their students.

One teacher expressed her ideas this way, "Every child in every school deserves an equal education. A zip code or a neighborhood shouldn't dictate the quality of a child's education." Another built on this by saying, "I need to know my kids are in a safe place, a place where they're being cared for, growing, and developing every day. Every child I teach deserves honor and respect." Doing what is right for children is the goal.

The mass transition to distant learning is playing out differently in each district across the country. Compare the experiences of Duval County Schools with the experiences in San Jose Unified School District. The experience in Duval County helps to illustrate the magnitude of the problem being faced by many school districts throughout the United States. The county made the decision to close schools and then in less than 72 hours, the transition team moved the entire district to an athome, virtual instruction model while also mobilizing the meal program, providing online teacher training, and completing a myriad of issues that came with the monumental change. During those three days, the district also created, printed, and distributed about 5 million pages of instructional content, loaded classes and content onto an online platform, and gathered additional online resources. Then they conducted a survey of the technology needs for their 130,000 students while readying thousands of computers for student use. Then they prepped for neighborhood delivery of school lunches and snacks so children would not go hungry and they accomplished all this while mobilizing a community of partners and volunteers [4].

However, some schools, meanwhile, have no immediate plans to move to mandated online learning. Students in California's San Jose Unified School District will receive no assignments or grades during their mandated three-week school closure [5]. Rather than attempting to create specific instruction for each class, the district provides suggestions for families seeking structure, guidance, and additional resources during this time at home. The district website lists a suggested daily schedule and choices of resources to help parents enhance their child's educational experiences [6].

Because of the magnitude of the challenges presented when attempting to put instruction online, perhaps the most important issues for school and district leaders right now is determining the steps that will make the biggest difference most quickly. This time of crisis might not be the time to think about what online or remote learning looks like in an ideal setting. Unless a district has done extensive preparation, leaders might want to consider rolling out distance learning in stages, starting with no-tech and low-tech approaches [5].

\section{Digital Impact}

With schools in all states now having formal closure mandates and with 46 of those states extending their original closure dates, the traditional face to face delivery of education has been disrupted. As 
of April $4^{\text {th }}, 17$ states had extended their mandated school closures through the rest of the academic year [7]. The significant logistic considerations of moving instruction online necessitate both planning and training [8].

Digital inequities become more evident as instruction moves online. It is difficult to provide the same quality of online education to every student when some learners are not able to access those resources. Children, who do not have access to a computer, or families where a single computer is shared by multiple siblings or family members, are at a disadvantage. The less affluent or digitally savvy families are, the more their students tend to be left behind because of the costs associated with digital devices and internet access [2]. Previously children without access to the internet at home could use libraries, community centers, and restaurants to access Wi-Fi, but because of the COVID-19 pandemic closures, these options are no longer available. In an attempt to address this issue, some businesses have taken the step of allowing individuals to access their Wi-Fi from cars in their parking lots.

Woolley et al. [9] reported that according to the 2019 Federal Communication Commission report around 21 million individuals in the United States do not have access to broadband internet at home. However, John Kahan, Microsoft chief data analytics officer, reported that his company's data indicated a more wide-spread problem. In their estimation, almost 163 million individuals do not have access to broadband internet.

During this crisis, many school districts across the country are distributing digital devices and WiFi hotspots to those students without the resources or ability to access online instruction [10]. Not every district is able to address the problems of digital access in the same way. Jefferson City Public Schools in Louisville, Kentucky, was able to distribute 25,000 Chromebooks to their students who did not have digital devices. New York City Schools, on the other hand, estimated that they had 300,000 students without access to digital devices. They announced plans to lend iPads with TMobile connections; however, they found they only had 25,000 devices to distribute. This, of course, raised concerns about academic achievement for those students who were not provided access to the needed instructional materials [9].

For those students who remain digitally challenged, public television stations in some parts of the U. S., including Los Angeles, New York, Detroit, Houston, Boston, Oklahoma, and Florida just to name a few, are attempting to fill the gap by providing families with academic-related programming [9]. RSU Public TV in Oklahoma is providing 3 hours of classroom instruction each day to viewers across 22 counties in northeastern Oklahoma. The station partnered with Tulsa Public Schools and Sequoyah Public School to bring lessons to students during this crisis enabling students in rural towns to continue their learning [11]. Even with the measures being taken in an attempt to close the digital divide, school closures could result in a widening of the achievement gap between lowand high-income students.

\section{Family Impact}

Although it would be wonderful if each student had a parent or caregiver available to work with them each day, this is not always feasible The child's caregiver may be working from home, having to go to work in an essential service industry, or having to split time and resources between children of varying ages, each with their own set of needs. One parent reported, “... it's definitely a burden. 
You have to adjust your life to be able to facilitate your child's learning when that's not what you're used to doing" [8].

Having multiple school-age children in the same household complicates online learning even further. A fifth-grade student may need help with a difficult mathematics lesson while the kindergartner needs help manipulating the computer. These difficulties are further confounded by children needing to use a variety of programs that require different logins and passwords that families now need to master.

\section{Academic Impact}

Although online learning content is being provided by many teachers, the online approach might not work equally well for each learner. Those students with disabilities or who are English Language Learners might be at more of a disadvantage than other learners. Parents have reported that some of the supplemental materials initially provided by teachers were not accessible to students with intellectual or physical disabilities [12].

UNESCO reported that the worldwide impact of COVID-19 would be particularly devastating for girls and women based upon what happened during the Ebola crisis in 2014-2016. Studies found that school closures increased girls' vulnerability to physical and sexual abuse. Most girls reported this increase in physical and sexual abuse was a direct result of being outside the protective environment provided by schools [13]. The World Health Organization [14] warned that although efforts to contain the coronavirus were vital to the health of the world's population, these same measures are also exposing children to increased risk of violence, cyber-bullying, maltreatment, gender-based violence, and sexual exploitation.

\section{Economic Impact}

As the COVID-19 crisis continues it affects the family's finances, as well. As businesses are closed in an attempt to stop the spread, employees are experiencing layoffs. Consequently, more adults are out of work, thus increasing the number of students needing to work in an attempt to support their struggling families. This economic challenge impacts students' ability to continue their education and the options available to these students upon graduation because of a lack of family resources to allocate toward higher education [15].

\section{Food Services}

\section{SUPPORT SERVICES}

The National School Lunch Program provides low-cost or free lunches to 29.7 million children in nearly 100,000 public and nonprofit PK-12 schools each school day. Free lunches are available to children living in households with incomes at or below 130 percent of the poverty level and reduced-price lunches are available to those children living in households between 130 and 183 percent of the poverty level. In 2018, nearly three-quarters of the 5 billion lunches served were free or reduced-price lunches [16].

Schools are now able to institute grab and go meals for those students who are food insecure [1] because the federal government has waived the requirement that meals be served and eaten in a congregate setting. This regulatory change resulted from an effort by the USDA to support social distancing during the COVID-19 crisis [17]. In the midst of the crisis, many school lunch employees 
are continuing to work so that free or reduced-price lunches can be provided to children in need. Some districts are even providing both breakfast and lunch for those children who are food insecure. These meals, which used to be available only during the school day, now are available for families to pick up from their local school. Because of the dedication of these employees, children who are food insecure are being fed [18].

\section{Guidance Services}

High school seniors are facing significant stress and challenges during the COVID-19 crisis. Students moving from high school to college face the increased stress of having to individually grapple with complicated financial aid packages and determine their anticipated out-of-pocket expenditures for higher education. School closures have limited students' access to teachers, counselors, and other staff members who can support them as they attempt to make important decisions about their futures [15].

But students transitioning from their K-12 program to higher education are not the only ones experiencing stress. With schools being closed, students have limited contact with others outside of their immediate family. Consequently, feelings of social isolation are occurring more frequently. Schools are developing social-emotional plans of action to be instituted in the remote learning setting. Many are completing wellness checks in an attempt to determine how kids and parents are doing emotionally [5]. Educators have realized that in addition to providing academic content they also need to help facilitate social interaction. Many districts are using social media platforms like FaceTime, WhatsApp, and Zoom to encourage students to communicate with their classmates [18]. Teachers have found Zoom to be an easy way for students to see and communicate with each other in an attempt to help them to stay emotionally healthy. Observing 15 kindergarteners and their teacher on a Zoom call was a memorable experience! The students were so excited to see each other and enthusiastically shared experiences.

As the COVID-19 crisis continues, the stress level is increasing. Students may express stress in many different ways. The Center for Disease Control and Prevention [20] indicated that stress can be exhibited through fear about ones' own health or that of others, changes in eating patterns, difficulty sleeping or concentrating, or worsening of chronic or mental health conditions. Even with school closures, guidance counselors have stepped in to try to address this increased stress. Counselors are making themselves available to support students during this crisis by answering students' questions, sharing ways to deal with stress, helping establish new routines or keeping up with regular routines, and by being a role model of normal healthy functioning and social connections. For example, Alachua County Schools, like many other school districts throughout the country, recognized the additional stress COVID-19 is placing on families and students. Because of this, families can contact school guidance counselors through phone or school email to set up appointments for phone or video chats to address student concerns [21].

\section{Academic Services}

Educators everywhere are rising to the occasion! Significant shifts in content presentation are occurring at unprecedented rates. One teacher reported, "In the last two weeks, I have had a lot of PD (both prescribed and personal) in order to be prepared for how we are delivering content in an online platform. All of a sudden, this training has become relevant and urgent." Another shared, "Our leaders are having to show grace and mercy to all stakeholders, including our 
Carver, L. (2020). Supporting Learners in Time of Crisis. Advances_in Social Sciences Research Journal, 7(4) 129-136.

employees. What is working for one employee right now might not be working for others. While one teacher may have a lot of technical training, there are others who only turn on their computer to take attendance and send an email. Learning is going to look very different for these two teachers and their students."

Even with the enormous challenges we are facing, teachers are making a difference for their students. One teacher shared, "Distance learning for my students is going well. We use a great communication tool called Class Dojo and $100 \%$ of my parents have the app so I can message them at any time. This app is something we have been using all year, but it is especially helpful right now during this crisis. I'm starting my students off slow and easy by having them complete an online lesson daily on iReady reading since they are familiar with it. I have been monitoring their daily progress and sending messages to them by providing "feedback" on their quizzes. I'm requiring them to read independently daily and encouraging them to take AR tests after they finish the book they are reading. They are getting math and science assignments from their content teachers and additional instruction from the art and music teachers." Districts who were already using digital resources might find the transition to online instruction easier than those who were not.

\section{Technology Business Services}

To support students, education technology companies have taken drastic measures to help educators reach students in virtual ways. In many cases, the technology companies have made their paid services free through the rest of the academic year. In other instances, they have removed limits to services and/or added premium features to what is currently available free. Google, Microsoft, Teams, and Zoom have remote learning tools that can be used by teachers to support teacher-created instruction. But creating content takes time, and with the rush to online instruction, time is a precious commodity. Teachers might find already constructed content particularly helpful. Businesses have made this available, too.

Companies are offering prepackage content through programs such as iReady and Achieve 3000 . Arizona State University is providing free access to field trips, puzzles, videos, and maps. BookCreator is supporting individual and collaborative writing skills by providing a free 90-day upgrade to its premium service. Second language support is being provided by Carnegie Learning iCulture and Babbel [22]. These are just a few of the many resources being offered by technology companies who are going above and beyond to help students succeed.

\section{CONCLUSION}

The idea of being able to just take what you have been doing in a face to face classroom and dropping it into an online course shell has its own problems. But attempting this transition in the midst of a pandemic creates other problems. Some individuals have jokingly named what we are doing right now as "Panic-gogy" (panic + pedagogy) [23]. But no matter what you call the process of moving from face to face to online instruction happening during this pandemic, supporting students is and should be the first concern.

Administrators, teachers, guidance counselors, cafeteria workers, educational technology companies, and a myriad of other volunteers and employees are working long hours attempting to meet the needs of all students. This is indeed a crisis, but the positive perspectives of educators is evidenced through the following comment. "My work hours are totally extended beginning at 7 and 
extending late into the night. I am handling everything from the parent concerns to emails from the school about online resources. It has been a major change, but I am thankful that I can still do my job. I am definitely blessed to be healthy, and my students are doing well. We can make it through! We were built for this!"

Reddy [19] emphasized the importance of supporting students with resilience and kindness as students are faced with the disruptions in their lives. These stressful times, though difficult and trying, give students and all of us an opportunity to develop the emotional resilience and which will help us to become more adept as leaders. Together we are making a difference for our children.

\section{References}

[1]. McCarthy, K. (2020, March 6). The global impact of coronavirus on education. ABC News. https://abcnews.go.com/International/global-impact-coronavirus-education/story?id=69411738

[2]. Tam, G. \& El-Azar, D. (2020, March 13). 3 Ways the coronavirus pandemic could reshape education. World Economic Forum https://www.weforum.org/agenda/2020/03/3-ways-coronavirus-is-reshaping-education-andwhat-changes-might-be-here-to-stay/

[3]. UNESCO. (2020, April 4). COVID-19 educational disruption and response. Author. https://en.unesco.org/covid19/educationresponse

[4]. Peel, C. \& Muller, B. (2020, March 18). Duval public schools to launch new home education program while campuses remain closed. News 4 Jax. https://www.news4jax.com/news/local/2020/03/17/duval-county-schoolleaders-looking-at-options-for-online-classes/

[5]. Zalaznick, M. (2020, March 17). Expert tips for shifting to online learning during COVID-19. District Administration. https://districtadministration.com/online-remote-distance-learning-education-covid-19-schoolsshift/

[6]. San Jose Unified School District. (2020). Update on San Jose Unified response to COVID-19. https://www.sjusd.org/whats-happening/news/a-letter-from-the-san-jose-unified-school-district/4340/

[7]. Nagel, D. (2020, April 9). Updated list of statewide school closures with closure dates. THE Journal. https://thejournal.com/Articles/2020/03/17/List-of-States-Shutting-Down-All-Their-Schools-Grows-to-36.aspx

[8]. Einhorn, E. (2020, March 16). As coronavirus closes schools, teachers and families brace for massive experiment in online education. ABC News. https://www.nbcnews.com/news/education/coronavirus-closes-schools-teachersfamilies-brace-massive-experiment-online-education-n1160966

[9]. Wooley, S., Sattiraju, N. \& Mortiz, S. (2020, March 26). U. S. schools trying to teach online highlight a digital divide. Bloomberg. https://www.bloomberg.com/news/articles/2020-03-26/COVID-19-school-closures-reveal-disparity-inaccess-to-internet

[10]. St. George, D., Natanson, H., Stein, P. \& Lumpkin, L. (2020, March 22). Schools are shut, so how will kids learn amid the COVID-19 pandemic? The Washington Post. https://www.washingtonpost.com/local/education/schoolsare-shut-so-how-will-kids-learn-amid-the-COVID-19-pandemic/2020/03/22/dac4742e-6ab7-11ea-992357073adce27c_story.html

[11]. Hughes, H. (2020, April 7). RSU public TV launching on-air educational broadcast during COVID-19 crisis. 8 ABC Tulsa. https://ktul.com/news/local/rsu-public-tv-launching-on-air-educational-broadcast-during-COVID-19-crisis

[12]. Preston, C. (2020, March 31). I hat COVID-19: Kids with disabilities struggle to adjust as schools close. NBC News Now https://www.nbcnews.com/news/education/i-hate-covid-19-kids-disabilities-struggle-adjust-schools-closen1172906

[13]. Giannini, S. (2020). COVID-19 school closures around the world will hit girls hardest. UNESCO. https://en.unesco.org/news/covid-19-school-closures-around-world-will-hit-girls-hardest 
Carver, L. (2020). Supporting Learners in Time of Crisis. Advances_in Social Sciences Research Journal, 7(4) 129-136.

[14]. World Health Organization. (2020, April 8). Violence against children: A hidden crisis fo the COVID-19 pandemic. https://www.who.int/news-room/detail/08-04-2020-joint-leader-s-statement---violence-against-children-a-hiddencrisis-of-the-covid-19-pandemic

[15]. Wang, J. (2020, March 20). How coronavirus could impact futures of students entering high school, college, UChicago News. https://news.uchicago.edu/story/how-coronavirus-could-impact-futures-students-entering-highschool-college

[16]. United States Department of Agriculture (USDA). (2019, August 20). National School Lunch Program. https://www.ers.usda.gov/topics/food-nutrition-assistance/child-nutrition-programs/national-school-lunchprogram/

[17]. United States Department of Agriculture (USDA). (2020). Nutrition program meal service during novel coronavirus outbreaks: Q \& As.

https://schoolnutrition.org/uploadedFiles/5_Learning_Center/13_Emergency_Planning/USDA-Child-NutrtionProgram-Meal-Service-During-COVID-19-Outbreaks.pdf

[18]. Pho, B. (2020, March 17). Grocers, food banks, and school lunch programs gear up to ensure residents have plenty of food. Voice of OC. https://voiceofoc.org/2020/03/grocers-food-banks-and-school-lunch-programs-gear-upto-ensure-residents-have-plenty-of-food/

[19]. Reddy, J. (2020, March 19). Faculty, staff address student concerns for coping with COVID-19 stigma and stress. The Cavalier Daily. https://www.cavalierdaily.com/article/2020/03/faculty-staff-address-student-concerns-forcoping-with-COVID-19-stigma-and-stress

[20]. Center for Disease Control and Prevention. (2020, April 1). Stress and coping. https://www.cdc.gov/coronavirus/2019-ncov/daily-life-coping/managing-stress-anxiety.html

[21]. Alachua County Public Schools. (2020). Coronavirus COVID-19. https://www.sbac.edu/Page/29814

[22]. Schaffhauser, D. (2020, April 10). Updated: Free resources for schools during COVID-19 outbreak. THE Journal. https://thejournal.com/Articles/2020/03/13/Free-Resources-Ed-Tech-Companies-Step-Up-During-CoronavirusOutbreak.aspx?Page=1

[23]. Kamenetz, A. (2020, March 19). Panic-gogy: Teaching online classes during the coronavirus pandemic. NPR. https://www.npr.org/2020/03/19/817885991/panic-gogy-teaching-online-classes-during-the-coronaviruspandemic. 